\title{
Is so-called Al-Mg isochron for a meteorite CAI a two component mixing line?
}

\author{
NOBORU NAKAMURA \\ Department of Earth Sciences, Faculty of Science, Kobe University, Nada-ku, Kobe 657, Japan
}

(Received August 24, 1984: Accepted May 21, 1985)

\begin{abstract}
An Al-Mg pseudo-isochron is expected for the type B inclusion (CAI) of carbonaceous chondrites on the basis of stoichiometry of anorthite (or hibonite). The linear correlation of excess ${ }^{26} \mathrm{Mg}$ with ${ }^{27} \mathrm{Al} /$ ${ }^{24} \mathrm{Mg}$ ratio found for the Allende and Leoville CAI's is well-interpreted as a result of mixing in various proportions $(<2 \%)$ of two end-members: one with no substantial excess of ${ }^{26} \mathrm{Mg}$ such as spinel, fassaite and melilite, and the other nearly pure anorthite with excess ${ }^{26} \mathrm{Mg}$ (possibly fossil ${ }^{26} \mathrm{Mg}$ ) or it's precursor. I would like to call attention to the difficulties in attaining to a "true" $\mathrm{Al}-\mathrm{Mg}$ internal isochron for meteorite CAI's.
\end{abstract}

\section{INTRODUCTION}

Discovery of the excess ${ }^{26} \mathrm{Mg}$ by Gray and Compston (1974) and Lee and Papanastassiou (1974) and the demonstration of Al-Mg internal isochron by Lee et al. (1977) for the Allende CAI's were crucial contributions to the understanding of existence of extinct ${ }^{26} \mathrm{Al}$ in the early solar system materials. The presence of ${ }^{27} \mathrm{Al}-$ correlated ${ }^{26} \mathrm{Mg}$ excesses in meteorite CAI's was reconfirmed by the later works of other groups (Hutcheon et al. 1978; Stegmann and Begemann 1981; Lorin et al. 1977). Based on the live ${ }^{26} \mathrm{Al}$ model, these workers obtained almost the same initial ${ }^{26} \mathrm{Al} /{ }^{27} \mathrm{Al}$ ratio of $\sim 5 \mathrm{X}$ $10^{-5}$ for the type B CAI's of the Allende and Leoville (C3) meteorites. The live ${ }^{26} \mathrm{Al}$ abundance in the earliest solar system materials estimated from the ratio is considered to be enough to melt a small planetary body as well as larger planets (Lee et al. 1977), which substantiates the previous idea (Urey 1955; Fish et al. 1960).

Validity of the Al-Mg isochron is of basic importance for evaluation of live ${ }^{26} \mathrm{Al}$ in the early solar system. As discussed by Lee et al. (1977), if an Al-Mg isotopic equilibration was established at the time of CAI formation then the linear correlation is eventually ascribed to in situ decay of ${ }^{26} \mathrm{Al}$ within the solar system. However, chemical and petrological works so far reached are not enough to clarify this problem, since the chemical and isotopic nature of CAI is so complex and has been still a controversial question.

In this article, I would like to point out a possibility that the linear $\mathrm{Al}-\mathrm{Mg}$ correlation of the meteorite CAI which has been normally interpreted as a "true" isochron may represent more or less a two-component mixing line, and to emphasize importance of further, basic searches for the $\mathrm{Al}-\mathrm{Mg}$ system of meteorite CAI's to establish its chronological meaning.

\section{Discussion}

\section{Isochron vs. two-component mixing line}

Among many isotopic analyses of $\mathrm{Al}-\mathrm{Mg}$ systems in the meteorite CAI's only three or four CAI's are known to have well-documented $\mathrm{Al}-\mathrm{Mg}$ internal isochrons (Lee et al., 1977; Hutcheon et al., 1978; Stegmann and Begemann, 1981; Hutcheon and Steele, 1980; Huneke et al., 1983). In any case the slope of isochron is defined solely by the data points of anorthites with different amounts of excess ${ }^{26} \mathrm{Mg}\left(\delta^{26} \mathrm{Mg}\right)$. 
The anorthites analyzed are reported to be "quite pure". Hence, in some cases, the Al concentrations in the mineral were calculated stoichiometrically via $\mathrm{Ca}$ determined by isotope dilution (Lee et al., 1977). The nearly stoichiometric concentration of $\mathrm{Al}$ in anorthite grains of CAI is rather clear for three CAI's under consideration. For example, deviations of the total chemical compositions within a large anorthite grain of the well-known Allende CAI WA from the stoichiometry $\left(\mathrm{CaAl}_{2} \mathrm{Si}_{2} \mathrm{O}_{8}\right)$ are only $1 \%$ or less for four areas examined by electron probe (and ion probe) micro-analyses, although large variations are observed for $\mathrm{Mg}$ content (240-570ppm) (Bradley et al., 1978). Similar features are also reported for other two CAI's (Hutcheon et al., 1978; Stegmann and Begemann, 1981). Such high anorthitic nature is considered to be general for the plagioclase of Allende CAI (Grossman, 1975). A highly pure mineral chemistry has been also found for a hibonite grain from the Dhajala ordinary chondrite for which a well defined $\mathrm{Al}-\mathrm{Mg}$ isochron was obtained (Honton and Bischoff, 1984).

Therefore, the ${ }^{27} \mathrm{Al}$ concentrations in anorthite or hibonite grains analyzed for $\mathrm{Al}-\mathrm{Mg}$ isochron plot are considered to be almost stoichiometric and thus approximated to be constant (k) normally within 3\% (possibly $5-10 \%$ in some cases (Stegmann and Begeman, $1981)) ;\left({ }^{27} \mathrm{Al}\right)=2 /\left(\mathrm{CaAl}_{2} \mathrm{Si}_{2} \mathrm{O}_{8}\right)=7.2 \times 10^{-3} \mathrm{~mol} /$ $\mathrm{g}$ for plagioclase and $\left({ }^{27} \mathrm{Al}\right)=12 /\left(\mathrm{CaAl}_{12} \mathrm{O}_{19}\right)=$ $1.8 \times 10^{-2} \mathrm{~mol} / \mathrm{g}$ for hibonite. If so, the so-called isochron relationship can be converted to a twocomponent mixing equation as follows, which is in commonest use for geochronologists (Faure, 1977) to test a validity of isochron:

$$
\begin{aligned}
{ }^{26} \mathrm{Mg} /{ }^{24} \mathrm{Mg}= & \mathrm{a}\left({ }^{27} \mathrm{Al} /{ }^{24} \mathrm{Mg}\right)+\mathrm{b} \\
& \text { Isochron relationship } \\
& (\mathrm{a}=\text { slope }, \mathrm{b}=\text { intercept }) \\
= & \mathrm{a} \mathrm{k} /\left({ }^{24} \mathrm{Mg}\right)+\mathrm{b} \\
& \begin{array}{l}
\text { Two-component mixing } \\
\text { relationship }
\end{array}
\end{aligned}
$$

Thus it turned out that regardless of validity of isochron the linear $\mathrm{Al}-\mathrm{Mg}$ correlation obtained for one Al-rich (stoichiometric) mineral and other $\mathrm{Mg}$-rich phases does potentially represent a two-component mixing line.

Therefore, the data points of anorthites or hibonite in an isochron are explicable by relatively small additions of Mg-rich phases into the nearly pure anorthite or hibonite with excess ${ }^{26} \mathrm{Mg}$ component. For ecample, let us consider spinel $(\mathrm{Mg}=17 \mathrm{wt} \%)$ to be $\mathrm{Mg}$-rich phase. In Fig. 1, a minor addition of spinel (e.g., 0-5\% mixing of spinel (Sp) in Fig. 1) yields extremely large variations in ${ }^{27} \mathrm{Al} /{ }^{24} \mathrm{Mg}$ ratio which substantially cover the whole excess ${ }^{26} \mathrm{Mg}$ data so

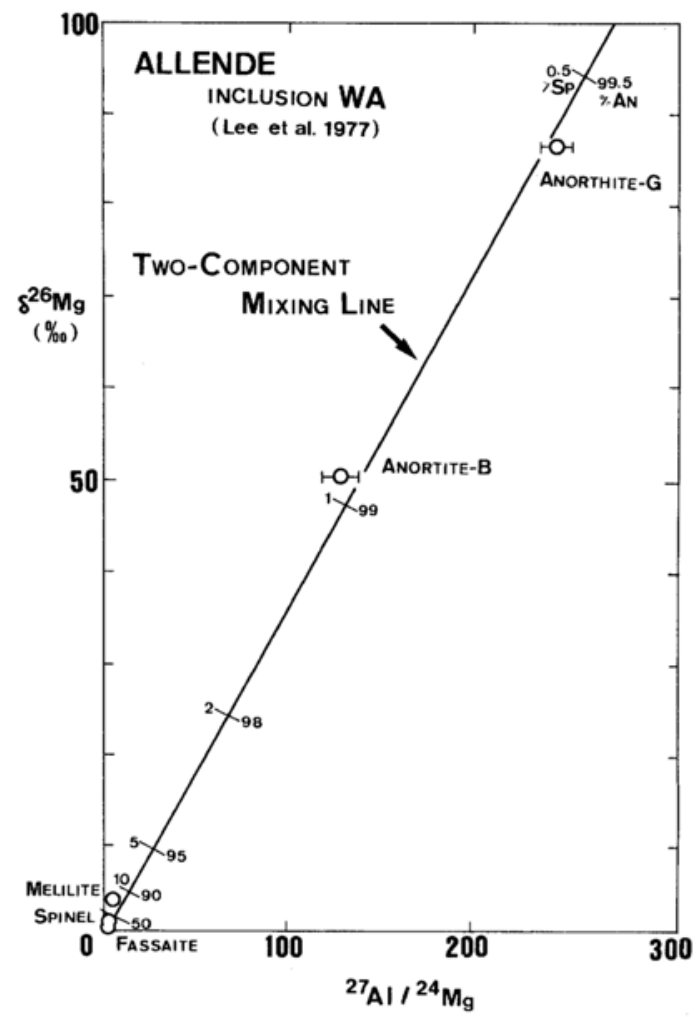

Fig. 1. Two-component mixing daigram for the Al-Mg system of meteorite CAI. The solid line is calculated on the assumption of mixing of varing proportions of spinel with no excess ${ }^{26} \mathrm{Mg}$ with anorthite with excess ${ }^{26} \mathrm{Mg}$ component: $a k=5.1 \times 10^{-5}\left({ }^{27} \mathrm{Al}\right)=3.7 \times 10^{-7} \mathrm{molg}^{-1}$. Note that variations of excess ${ }^{26} \mathrm{Mg}$ observed for many meteorite CAI's, typically the Allende CAI WA (Lee et al., 1977), are explained by minor addition (less than $2 \%)$ of spinel to the anorthite. Symbols Sp and An represent spinel and anorthite, respectively. 
far observed for the meteorite CAI's: data points of anorthites in WA isochron obtained by Lee et al. (Fig. 1) (Lee et al., 1977) are explained by addition of $0.5-1 \%$ spinel to the anorthite. In the same way the other CAI isochrons (Hutcheon et al., 1977; Stegmann and Begemann, 1981; Hutcheon and Steele, 1980; Huneke et al., 1983) are also explained by addition of mostly less than $0.5 \%$ (up to $1.8 \%$ ) spinel.

The linear $\mathrm{Al}-\mathrm{Mg}$ correlations for meteorite CAI's have been interpreted normally by isochron model (Lee et al., 1977; Hutcheon et al., 1977; Stegmann and Begemann, 1981) or the ad hoc mixing model (Clayton, 1977a). These workers, however, seem to have dismissed the stoichiometric view as expressed above.

Was Al-Mg system realy in equilibrium at the time of CAI formation?

Because anorthite and hibonite have no crystal site for $\mathrm{Mg}, \mathrm{Mg}$ in the minerals may exist as micro or submicron $\mathrm{Mg}$-rich inclusions dispersed within anorthite grains like "Fremdlinge" (Goresy et al., 1978), or possibly in lattice deffects or deformed crystal sites. In this respect, detailed searches for excess ${ }^{26} \mathrm{Mg}$ as well as normal $\mathrm{Mg}$ by Bradley et al. (1978), Hutcheon et al. (1978) and Huneke et al. (1983) are valuable. They found heterogeneous and large variations of normal $\mathrm{Mg}(300-1,000 \mathrm{ppm})$ and homogeneous distributions of excess ${ }^{26} \mathrm{Mg}$ components within anorthite grains. They detected no particular excess ${ }^{26} \mathrm{Mg}$ carriers larger than several $\mu \mathrm{m}$ size in anorthite such as $\mathrm{Al}_{2} \mathrm{O}_{3}$-grains as suggested by Clayton (1977a), and thus the results appeared to be consistent with the ${ }^{26} \mathrm{Al}^{-26} \mathrm{Mg}$ isochron model. However, it is pointed out that this situation is quite similar to that of oxygen isotopic anomaly of meteorite CAI's for which two-components mixing relationship has been well-established by Clayton group; Clayton et al. (1977) had also failed to identify any ${ }^{16} \mathrm{O}$-carried phase in CAI's.

It is thus possible that the large variations of the ${ }^{27} \mathrm{Al} /{ }^{24} \mathrm{Mg}$ ratios of anorthite are results of the heterogeneous distributions of $\mathrm{Mg}$-inclusions within the mineral grains. The question then arises whether the $\mathrm{Mg}$-inclusions were cogenetic with anorthite from a same reservoir and the normal $\mathrm{Mg}$ isotopes were in equilibrium with $\mathrm{Al}$ ? In this connection, it is interesting that some type B CAI's (B1) have the clear Al-Mg correlation but the B2's exhibit larger dispersions from the isochron with somewhat lower slope (Hutcheon and Steele 1980). Similar trend of the $\mathrm{Al}-\mathrm{Mg}$ system has been found even for a single B1 CAI, the well-known Allende CAI WA (Huneke et al., 1983).

From these $\mathrm{Al}-\mathrm{Mg}$ isotopic data, as well as many other chemical and isotopic characteristics of CAI's so far reported, it is suggested that the majority of $\mathrm{Al}-\mathrm{Mg}$ systems of meteorite CAI's were more or less lacking in complete isotopic equilibration at the time of formation or subjected to post-formation disturbances (Meeker et al., 1983). As argued by Wood (1981), discovery of heterogeneous distributions of isotopes and elements in CAI's and their unusual petrologic features have led cosmochemists to believe that precursor materials of CAI's were formed in different stellar environments and then mixed into the presolar system interstellar medium and the independently-formed dust grains had been subjected to reheating, melting and/or distillation, back-reaction with the distilled-off vapor or recondensates and so on, which might have led to metamorphic to igneous origin of CAI's. It is thus possible that some type B CAI's were formed from partial to total melts (Kurat et al., 1975; Blander and Fuchs 1975; Wark et al., 1982) or by sub-solidus sintering of pre-existed dust grains, and therefore some CAI's (Nagasawa et al., 1977) might have attained chemical equilibrium but some others were in incomplete equilibration (Palme and Wlotzka 1979; Nagasawa et al., 1982), depending on their formation conditions.

It should be noted that as far as we know there is neither clear evidence that the $\mathrm{Al}-\mathrm{Mg}$ isotopic equilibration was established at the time of CAI formation nor other experimental base such as diffusion data applicable to the CAI 
which might constrain the basic criteria of the $\mathrm{Al}-\mathrm{Mg}$ isochron.

Therefore, the meaning of the age or the initial ${ }^{26} \mathrm{Al} /{ }^{27} \mathrm{Al}$ ratio deduced from these isochrons is solely model dependent; for example, the age represents the stellar time scale (Clayton, $1977 b$ ) or the early solar system time sclae (Lee et al., 1977).

\section{Conclusion}

Because of stoichiometry of Al-rich minerals the reported Al-Mg internal isochrons for meteorite CAI's (Lee et al., 1977; Hutcheon et al., 1978; Stegmann and Begemann, 1981; Hutcheon and Steele, 1980; Hunkeke et al., 1983; Hinton and Bishoff, 1984) are well-interpreted as twocomponent mixing lines between $\mathrm{Mg}$-rich phase such as spinel, fassaite and melilite, and nearly pure anorthite or hibonite with fossil ${ }^{26} \mathrm{Al}$. Therefore, a live ${ }^{26} \mathrm{Al}$ model for the time scale and heat source of planetary bodies in the early solar system are still uncertain. In order to clarify the validity of so-called $\mathrm{Al}-\mathrm{Mg}$ isochron for a meteorite CAI, more detailed searches for distributions of $\mathrm{Mg}$ and $\mathrm{Al}$ isotopes (possibly submicron order examinations) would be required.

Acknowledgements-Prof. H. Nagasawa is acknowledged. We had stimulative discussions during my occasional visits to Gakushuin Univ. campus for isotope ball-games as well as playing tennis. I thank Prof. M. Ozima and anonymous reviewers for helpful comments on the manuscript, and Mmes. H. Wada and J. Asakura for typing the manuscript.

The work is supported in part by Grant in Aid from the Ministry of Education, Science and Culture (No. 59540367).

\section{REFERENCES}

Blander, M. and Fuchs, L. H. (1975) Calcium-aluminum-rich inclusions in the Allende meteorite: evidence for a liquid origin. Geochim. Cosmochim. Acta 39, 1605-1619.

Bradley, J. G., Huneke, J. C. and Wasserburg, G. J. (1978) Ion microprobe evidence for the presence of excess ${ }^{26} \mathrm{Mg}$ in an Allende anorthite crystal. $J$. Geophys. Res. 83, 244-254.
Clayton, D. D. (1977a) Cosmoradiogenic ghost and the origin of $\mathrm{Ca}-\mathrm{Al}$-rich inclusions. Earth Planet. Sci. Lett. 35, 433-454.

Clayton, D. D. (1977b) Solar system isotopic anomalies: Supernova neighbor or presolar carriers? Icarus 32, 244-269.

Clayton, R. N., Onuma, N., Grossman, L. and Mayeda, T. K. (1977) Distribution of the presolar component in Allende and other carbonaceous chondrites. Earth Planet. Sci. Lett. 34, 209-224.

Faure, G. (1877) Principles of isotope geology, 97-106. John Wiley \& Sons: New York.

Fish, R. A., Goles, G. G. and Anders, E. (1960) The record in the meteorites. III. On the development of meteorites in asteroidal bodies. Ap. J. 132, 243258.

Goresy, A. El., Nagel, K. and Ramdohr, P. (1978) Fremdlinge and their noble relatives. Proc. Lunar Sci. Conf. 9th. 1279-1303.

Gray, C. M. and Compston, W. (1974) Excess ${ }^{26} \mathrm{Mg}$ in the Allende meteorite. Nature 251, 495-497.

Grossman, L. (1975) Petrology and mineral chemistry of Ca-rich inclusions in the Allende meteorite. Geochim. Cosmochim. Acta 39, 433-454.

Hinton, R. W. and Bischoff, A. (1984) Ion microprobe magnesium isotope analysis of plagioclase and hibonite from ordinary chondrites. Nature 308, 169-172.

Huneke, J. C., Armstrong, J. T. and Wasserburg, G. J. (1983) FUN with PANURGE: High mass resolution ion microprobe measurements of $\mathrm{Mg}$ in Allende inclusions. Geochim. Cosmochim. Acta 47, 16351650.

Hutcheon, I. D., Steele, I. M., Smith, J. V. and Clayton, R. N. (1978) Ion microprobe, electron microprobe and cathodoluminescence data for Allende inclusions with emphasis on plagioclase chemistry. Proc. Lunar Planet. Sci. Conf. 9th. 1345-1368.

Hutcheon, I. D. and Steele, I. M. (1980) Mineralogy and $\mathrm{Mg}$ isotopic composition of type B2 inclusions from Leoville and Allende. Lunar Planet. Sci. XI 496-498.

Kurat, G., Hoinkes, G. and Fredriksson, K. (1975) Zoned $\mathrm{Ca}-\mathrm{Al}$-rich chondrule in Bali: new evidence against the primordial condensation model. Earth Planet. Sci. Lett. 26, 140-144.

Lee, T. and Papanastassiou, D. A. (1974) Mg isotopic anomalies in the Allende meteorite and correlation with $\mathrm{O}$ and $\mathrm{Sr}$ effects. Geophys. Res. Lett. 1, 225228.

Lee, T., Papanastassiou, D. A. and Wasserburg, G. J. (1977) ${ }^{26} \mathrm{Al}$ with early solar system: Fossil or fuel? Astrophys. J. 211, L107-L110.

Lorin, J. -C., Shimizu, N., Christophe Michel-Levy, M. and Allègre, C. (1977) The $\mathrm{Mg}$ isotope anomaly 
in carbonaceous chondrites: An ion-probe study. Meteoritics 12, 299-300.

Meeker, G. P., Wasserburg, G. J. and Armstrong, J. T. (1983) Replacement textures in CAI and implications regarding planetary metamorphism. Geochim. Cosmochim. Acta 47, 707-721.

Nagasawa, H., Blanchard, D. P., Jacobs, J. W., Brannon, J. W., Philpotts, J. A. and Onuma, N. (1977) Trace element distribution in mineral separates of the Allende inclusions and their genetic implications. Geochim. Cosmochim. Acta 41, 1587-1600.

Nagasawa, H., Blanchard, D. P., Shimizu, H. and Masuda, A. (1982) Trace element concentrations in the isotopically unique Allende inclusion, EK1-4-1. Geochim. Cosmochim. Acta 46, 1669-1673.

Palme, H. and Wlotzka, F. (1979) A Ca, Al-rich inclusion from the Leoville (C3V) meteorite. Mete- oritics 14, 508-511.

Stegmann, W. and Begemann, F. (1981) Al-correlated ${ }^{26} \mathrm{Mg}$ excess in a large $\mathrm{Ca}-\mathrm{Al}$-rich inclusion of the Leoville meteorite. Earth Planet. Sci. Lett. 55, 266272.

Urey, H. C. (1955) The cosmic abundances of potassium, uranium, and the heat balance of the earth, the moon, and mars. Proc. Nat. Acad. Sci. U.S. 41, 127-144.

Wark, D. A. and Lovering, J. F. (1982) The nature and origin of type B1 and B2 Ca-Al-rich inclusions in the Allende meteorite. Geochim. Cosmochim. Acta 46, 2581-2594.

Wood, J. A. (1981) The interstellar dust as a precursor of $\mathrm{Ca}, \mathrm{Al}$-rich inclusions in carbonaceous chondrites. Earth Planet. Sci. Lett. 56, 32-44. 